\title{
STUDY ON SHOCK RESULTING FROM STIMULATION OF THE PALATINE AREA BY COCAINE AND ITS PROPHYLAXIS IN GUINEA PIGS
}

\author{
YASUNOBU SUZUKI,* HISAO FUKAZAWA, \\ USHIO YANO, and MAKOTO SAKAI \\ Department of Otorhinolaryngology, School of Medicine, \\ Keio University, Tokyo, Japan
}

(Received for publication November 20, 1968)

\section{INTRODUCTION}

Many of otorhinolaryngologists are very apt to encounter a development of shock after an injection of local anesthetic drugs in the palatopharyngeal region during surgery.

Suzuki et $a l .^{1,2}$ reported statistics of the surgical shock in the otorhinolaryngological procedures and called an attention to the fact that fifty-three per cent of all surgical shocks was followed by an injection of local anesthetics. In 1963 Suzuki and his collaborators had also reported an extensive study of Reilly's phenomenon, sydrome d'irritation, connecting with the otorhinolaryngological field and had stressed that a peculiarity of the region of head and neck which contained many great vessels and nerves was responsible to the development of shock after an excessive irritation was added to the autonomic nervous system in this paticular region. In this study they had also found that the shock could be prevented by parenteral administration of chlorpromazine before the palatopharyngeal area was irritated by an injection of croton oil.

The purpose of this current study is to report an experimental evidence in which cocaine hydrochloride produced shock more frequently if it was given by submucosal injection into the palate of guinea pigs than if given by hypodermic or intravenous injection, and the shock was successfully prevented

* Professor of Otorhinolaryngology. 
by administration of chlorpromazine prior to an injection of cocaine in the palate.

\section{METHODS AND MATERIALS}

Healthy guinea pigs weighing 350 to $400 \mathrm{~g}$ including both sexes were selected as the experimental animals. Before attempting the main experiment on the animals, it was necessary to determine the sufficient amount of cocaine producing shocklike symptoms when it was given into the submucosal tissue of the palate. Table 1 shows the mortality rate from shock according to each concentration and amount of cocaine injected into the submucosal layer of the palate of the animals or into the hypodermis of the abdominal wall.

Table 1

\begin{tabular}{|c|c|c|c|c|c|c|}
\hline \multirow[b]{2}{*}{$\begin{array}{l}\text { Conc. \& amount of } \\
\text { cocaine } \mathrm{HCl}\end{array}$} & \multicolumn{3}{|c|}{$\begin{array}{l}\text { Injected to submucosal layer } \\
\text { of palate }\end{array}$} & \multicolumn{3}{|c|}{$\begin{array}{l}\text { Injected to hypodermis of } \\
\text { abdominal wall }\end{array}$} \\
\hline & $\begin{array}{l}\text { No. of } \\
\text { surv. }\end{array}$ & $\begin{array}{l}\text { No. of } \\
\text { death }\end{array}$ & Total & $\begin{array}{l}\text { No. of } \\
\text { surv. }\end{array}$ & $\begin{array}{l}\text { No. of } \\
\text { death }\end{array}$ & Total \\
\hline $20 \% \quad 0.3 \mathrm{cc}$ & 0 & $2=(100 \%)$ & 2 & 0 & $2(100 \%)$ & 2 \\
\hline $10 \% \quad 0.3 \mathrm{cc}$ & 0 & $3(100 \%)$ & 3 & 0 & $\therefore 2(100 \%)$ & 2 \\
\hline $10 \% \quad 0.2 \mathrm{cc}$ & 0 & $2(100 \%)$ & 2 & 0 & $2(100 \%)$ & 2 \\
\hline $10 \% 0.1 \mathrm{cc}$ & 0 & $3(100 \%)$ & 3 & 3 & $0(0 \%)$ & 3 \\
\hline $5 \% \quad 0.2 \mathrm{cc}$ & 3 & $0(0 \%)$ & 3 & 2 & $0(0 \%)$ & 2 \\
\hline
\end{tabular}

In guinea pigs injected $0.3 \mathrm{ml}$ of $20 \%, 0.3 \mathrm{ml}$ of $10 \%$ or $0.2 \mathrm{ml}$ of $10 \%$ cocaine, all died from shock regardless to the route of administration. Cocaine in $0.1 \mathrm{ml}$ of $10 \%$ solution ( 25 to $28 \mathrm{mg}$ per $\mathrm{kg}$ of body weight) produced shock

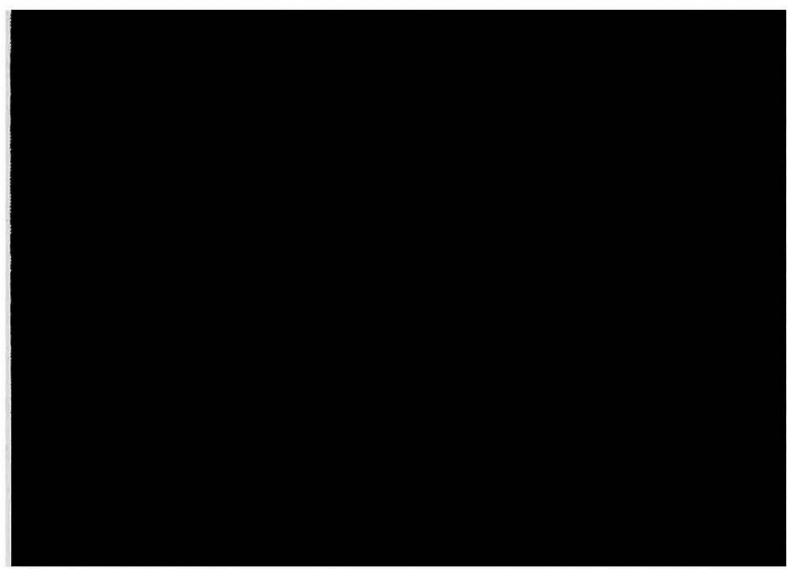

Picture 1 
and death in the animals when it was given by submucosal injection to the palate but produced no shock or death in the animals when given by hypodermic injection to the abdominal wall. The interesting result was that the animals given $0.1 \mathrm{ml}$ of $10 \%$ cocaine in the palate died from shock but no animals given $0.2 \mathrm{ml}$ of $5 \%$ cocaine, which was equivalent to $0.1 \mathrm{ml}$ of $10 \%$ solution, died from shock (Picture 1).

\section{EFFECT OF COCAINE IN THE DIFFERENT ROUTES OF ADMINISTRATION}

Another group of 21 guinea pigs were given $0.1 \mathrm{ml}$ of $10 \%$ cocaine by submucosal injection in the palate and died from shock within five minutes after the injection. The first recognizable symptom of shock was manifested in opisthotonos, tonic convulsion of the limbs within 30 seconds to 3 minutes after the injection. The shock became advanced and was followed by disability of keeping posture, cyanosis, an increase in the heart rate, labored respiration and finally the animals died from respiratory and cardiac arrest.

No death occured in 20 animals, those were given $0.1 \mathrm{ml}$ of $10 \%$ cocaine by hypodermic injection to the abdominal wall, within two hours after the injection (Table 2).

Table 2

\begin{tabular}{l|c|c|c}
\hline & No. of surv. & No. of death & Total \\
\cline { 2 - 3 } Submucosal inj. of palate & 0 & $21(100 \%)$ & 21 \\
Hypodermic inj. of abd. wall & 20 & $0(0 \%)$ & 20 \\
I.V. inj. of femoral vein & 13 & $7(35 \%)$ & 20 \\
Chlorpromazine treated & 20 & $0(0 \%)$ & 20 \\
\hline
\end{tabular}

Since the palatine mucosa is more vascular than the abdominal wall, the prime concern was to eliminate the fact that cocaine may gain an easy access to the circulation resulting in death of the animals from acute intoxication of the drug. Accordingly cocaine was injected directly into blood stream via the femoral vein of 20 animals. The result is shown in Table 2. From shock 7 out of 20 were immediately died and 13 survived for more than two hours after the injection.

The results indicate that in the animals given cocaine into the submucosal tissue of the palate shock is not caused by acute intoxication of cocaine. 


\section{PREVENTION OF SHOCK BY ADMINISTRATION OF CHLORPROMAZINE}

Chlorpromazine, $1 \mathrm{mg}$ per body weight in $0.01 \%$ solution divided to three doses, was injected, according to Fukazawa, ${ }^{3}$ in the abdominal wall of guinea pigs one, two and three hours before an injection of cocaine in the submucosal tissue of the palate, as in a guinea pig weighed $350 \mathrm{~g}$ chlorpromazine $0.5 \mathrm{ml}$, $1.0 \mathrm{ml}$ and $1.5 \mathrm{ml}$ were injected three, two and one hour before an injection of cocaine respectively. Table 2 shows that 10 out of 20 guinea pigs premedicated with chlorpromazine developed shocklike symptoms which, however, subsided within 10 to 30 minutes after an injection of cocaine, and no death was recorded. The other 10 animals developed no shocklike symptoms.

Administration of chlorpromazine could effectively prevent or reduced a development of shocklike reaction to cocaine in guinea pigs.

\section{HISTOPATHOLOGICAL FINDINGS}

All animals were necropsied after death from shock or after stunned and killed two hours after an injection of cocaine and the lungs, kidneys, adrenal glands and livers were obtained and fixed with formalin solution, embedded in paraffin and stained with hematoxylin-eosin. The animals given an injection of cocaine into the submucosal tissue of the palate revealed more distinct changes of the circulatory system of those organs, i.e. congestion, edema and hemorrhage, than the animals given cocaine in the abdominal wall or in the femoral vein, or the animals premedicated with chlorpromazine. In the animals given chlorpromazine before an injection of cocaine and recovered from shocklike symptoms was the rather remarkable changes in the lungs and it may be related to the duration and intensity of the convulsive seizure followed an injection of cocaine. The pathological changes of each organ of the animals given an injection of cocaine into the femoral vein were not as severe as that of the animals injected cocaine into the submucosal tissue of the palate.

\section{DISCUSSION}

It has been supported by many researchers that the cause of shock followed an injection of cocaine is due to acute intoxication of the drug with which the toxic blood concentration is rapidly reached. This is due to accidental intravenous injection or to absorption of an excessive quantity in a very short time.

Eidens, ${ }^{4}$ De Takats $^{5}$ postulated that the reaction to the local analgesic solution was due to a surgeon's mishap in which he injected the drugs into 
vessels. Fussgaenger et $a l .{ }^{6}$ stated after clinical observation and animal experiment that acute death due to the local anesthetics was caused by acute intoxication of the drugs that produced respiratory arrest.

Hirschfelder et al. ${ }^{7}$ also supported the idea in which the respiratory system was more susceptible to the local anesthetic drugs than the cardiovascular system and the cause of death after an injection of the drugs was respiratory failure. Tatum and his associates ${ }^{8,9}$ reported experiments on dogs in which the mortality rate of dogs injected cocaine paralleled to the duration of convulsive seizure and the rapid and shallow respiration was followed by respiratory arrest, and they concluded that the cause of death from cocaine was depression of the vital medullary centers and the cerebral cortex.

Knoefel ${ }^{10}$ stated that the administration of a large intravenous dose of cocaine might result in immediate death from cardiac failure due to a direct toxic action on heart muscle, and the administration of a small subcutaneous dose might result in convulsive death either from failure of the respiratory center or from stimulation of the cerebral cortex.

However, Shumaker ${ }^{11}$ and Sollman ${ }^{12}$ stated that a development of cocaine intoxication depended not on the blood concentration of cocaine but on the rapidity with which the toxic blood concentration was reached, and the cardiac death might be caused by the rapid absorption and the convulsive death by the slow absorption. Goodman and his co-workers ${ }^{13}$ stated that the intravenous administration of a large quantity of cocaine might result in death from cardiac failure due to a toxic action directly on heart muscle, and Senda ${ }^{14}$ sustained this idea and stated that death from cocaine intoxication was due to a direct action of cocaine on heart muscle. Young et al.15 also postulated that the cause of death from cocaine poisoning was cardiovascular failure, and called an attention to the considerable individual variation in susceptibility to cocaine and the administration of an excessive dose of the drug.

Sadove and his co-workers ${ }^{16}$ thought the blood concentration of cocaine as an important factor contributing to cocaine intoxication and postulated that the cause of death was cardiovascular failure.

All of the researchers mentioned above have unanimous agreement with the opinion that death from cocaine may be caused by the acute intoxication following the administration of the drug in a large amount, even though they would not come to a conclusion whether a massive dose of cocaine may result in cardiovascular failure or in respiratory failure.

However, the authors' experiment indicates that shock and death after an injection of cocaine into the submucosal tissue of the palate may not be caused 
by absorption of cocaine in blood, because there is the fact that intravenous administration of the drug into the femoral vein of guinea pigs caused not as much death as the submucosal administration of cocaine in the palate. The authors strongly believe that the autonomic nervous system may play an important role in the development of shock and death from cocaine which is injected in the palate.

The reasons why the authors came to this thought are that $100 \%$ mortality was subsequent to the submucosal injection of cocaine in the palate but $0 \%$ mortality followed the intramuscular injection in the abdominal wall; that the mortality rate was lower in the animals in injected cocaine directly into blood stream via the femoral vein than in those given the drug in the submucosal tissue of the palate; that there was the similarlity of pathological changes of the animal organs such vascular embarrassment as congestion, edema or hemorrhage within the tissue of the animals in this experiment to the histopathology of Reilly's phenomenon. Furthermore, the authors would stress the fact that the submucosal injection of $0.1 \mathrm{ml}$ of $10 \%$ cocaine, 25 to $28 \mathrm{mg} / \mathrm{kg}$, in the palate could cause shocklike symptoms in guinea pigs but the injection of $0.2 \mathrm{ml}$ of $5 \%$ cocaine in which the actual amount of cocaine is equal to $0.1 \mathrm{ml}$ of $10 \%$ solution could cause no symptoms whatsoever. Because of the vasoconstrictive property of cocaine it is believed that cocaine in high concentration is absorbed in blood from the injected site in slower rate than cocaine in low concentration, but the authors' experiments indicates that cocaine in high concentration is more susceptible to the development of shocklike symptoms. The explanation offered to account this phenomenon is that cocaine in high concentration may stay in the site of injection for a long period of time and this may be capable of being an excessive irritation to the autonomic nervous system in the region of cocaine injection and may be an important factor contributing to the development of shocklike symptoms.

How can cocaine be an excessive irritation to the autonomic nervous system when it is given by submucosal injection in the palate? As Walter Arthur Bastedo"17 described the action of cocaine in his work "Pharmacology Therapeutics and Prescription Writing" in which he wrote "necrosis of the site of injection or aseptic abscess is common if cocaine is taken by subcutaneous injection and the cornea may become dry and clouded, and ulcerlation may follow if cocaine is used on the eye," cocaine is a cytotoxic drug and it may irritate and destruct living cells. Therefore, as experiments of Suzuki et al. ${ }^{27}$ showed that croton oil became an excessive irritation to the autonomic nervous system and produced shock in the animals when it was given by submucosal in- 
jection in the palate, cocaine had the same property producing an excessive irritation to the autonomic nervous system. Cocaine is also believed to be the sympathomimetic drug because of its vasoconstrictive effect, mydriatic and pressor effect.

The authors, therefore, postulate that the autonomic nervous system may play an initiative role in the development of shock and death when cocaine, such a sympathomimetic drug, is administered by the submucosal injection in the palate where the autonomic nervous system is abundant.

Since Tatum et al.8,9 had used barbiturates for prevention of experimental cocaine poisoning, Steinhaus, ${ }^{12,18}$ Leshure, ${ }^{19}$ Ferguson, ${ }^{20}$ Knoefel, ${ }^{10}$ Himalstein, ${ }^{21}$ Tella, ${ }^{22}$ Williams, ${ }^{23}$ Martin, ${ }^{24}$ Barlow $^{25}$ have studied the prophylactic effect of barbiturates against acute cocaine intoxication. They stated that the anticonvulsive action of barbiturates was mostly effective for the prevention of cocaine poisoning.

Hou ${ }^{26}$ had reported the prophylactic use of Grelan for experimental poisoning of cocaine on guinea pigs and stated "Grelan is a preparation of pyrabital, aminopyrine and urethan, and anti-convulsive effect of pyrabital, anti-convulsive and respiratory center stimulating effect of urethan and vasodilating effect of aminopyrine are useful for prevention of cocaine intoxication." Fukazawa $^{3}$ reported an experimental evidence in which guinea pigs were treated with chlorpromazine before they had intramucosal injection of croton oil in the palate, and showed that chlorpromazine prevented a development of shock and death in these animals. He also postulated that chlorpromazine depresses directly or indirectly function of the autonomic nervous system and promotes stabilization of environment, depression of function of the adrenal cortex and reduction of metabolism.

The authors also show the prophylactic effect of chlorpromazine for a development of shock and death from cocaine intoxication as described in the preceding part of this report showing 10 out of 20 guinea pigs premadicated with chlorpromazine resulted in no shocklike symptoms and the other 10 resulted in shocklike symptoms which, however, subsided within 30 minutes and no death in 24 hours' duration of this experiment. The pathological changes in each organ of the premedicated animals were recorded as much milder than that of the non-premedicated animals.

From the results of this experiment, it is said that the premedication with chlorpromazine is sufficiently effective for prevention of a development of shock from cocaine intoxication. 


\section{SUMMARY AND CONCLUSIONS}

1) Guinea pigs were given submucosal injection of cocaine, $0.1 \mathrm{ml}$ of $10 \%$ solution $(25-28 \mathrm{mg} / \mathrm{kg})$ in the palate, and all of 21 animals developed shocklike symptoms and died. Twenty animals received the same amount of cocaine by subcutaneous injection in the abdominal wall and no death was recorded. This result shows that there is the pecuriality of the palate to be injected cocaine.

2) Seven out of $20(35 \%)$ died after they were given intravenous injection of cocaine into the femoral vein. The mortality was much lower than that of animals given cocaine by submucosal injection. This result shows there is no shock or death from cocaine intoxication produced by absorption of the drug into blood.

3) Pathological changes such as congestion, edema and hemorrhage in tissue of each organ of the animals were much prominent in those given cocaine by submucosal injection in the palate. These findings are very similar to that found in Reilly's phenomenon.

4) Shock and death from submucosal injection of cocaine into the palate is the result of Reilly's phenomenon in which the injection of cocaine becomes an excessive irritation to the autonomic nervous system in the palate where the autonomic nervous system is abundant.

5) Shock and death from cocaine is successfully prevented by the administration of chlorpromazine, the autonomic nerve blocking agent.

\section{REFERENCES}

1. Suzuki, Y. et al.: Shock and otorhinolaryngological surgery. Otolaryngology, 30: $153,1962$.

2. Suzuki Y. et al.: Shock and otorhinolaryngological surgery. Jap. Jour. Otol., 65: 1057, 1962. (in Japanese).

3. Fukazawa, H.: Study on shock and death resulting from irritation of the palate of guinea pigs. Otolaryngology 30: 169, 1958.

4. Eidens, R.: Tod nach Novocaineanesthesie. Arch. f. klin. Chirur., 122: 603, 1923.

5. De Takats: Local Anesthesia. Saunders, Philadelphia, 1928.

6. Fussgaenger, R.: Ueber ein neues Lokalanaesthetikum der Novokainreihe (Pantokain) Arch. f. exper. Path. u. Pharmakol., 160: 53, 1931.

7. Hirschfelder, A. D.: Local Anesthetics. Phisiol. Rev., 12: 190, 1932.

8. Tatum, A. L.: Acute cocaine poisoning, its prophylaxis and treatment in laboratory animals. J. Pharmacol. and Exper. Therap., 26: 325, 1925.

9. Tatum, A. L.: Acute cocaine poisoning, preliminary report of an experimental study. Jour. Amer. Med. Assoc., 84: 1177, 1925. 
10. Knoefel, P. K.: Prevention of acute intoxication from local anesthetics. J. Pharmacol. and Exper. Therap., 39: 397, 1930.

11. Schumaker, H. B.: Reaction to local anesthetic agents. Surg., 10: 119, 1941.

12. Sollman, T.: A manual of pharmacology and its application to therapeutics and toxicology. W. B. Saunders Co., Philadelphia and London, 1942.

13. Goodman, L.: The Pharmacological Basis of Therapeutics. Macmillan Co., New York, 1941.

14. Senda, C.: Experimental study on cocaine poisoning and its treatment. Jap. Jour. Otol., 48: 399, 1942.

15. Young, D.: Electrocardiographic changes resulting from acute intoxication (cocaine). Amer. Heart Jour., 34: 272, 1947.

16. Sadove, M. S.: Classification and management of reaction to local anesthetic agents. J. A. M. A., 148: 17, 1952.

17. Bastedo, W. A.: Pharmacology Therapeutics and Prescription Writing. Saunders, Philadelphia, 1947.

18. Steinhaus, J. E.: An experimental study of cocaine intoxication and its treatment. J. Pharmacol. and Exper. Therap., 100: 351, 1950.

19. Leshure, J.: Barbital as preventive of cocaine toxicosis. Anesth. and Analg., 6: $189,1927$.

20. Ferguson, J.: The clinical and experimental comparison of cocaine and pantocaine as topical anesthetics in otolaryngological practice. Otolaryngology, 61: 767, 1951.

21. Himalstein, M. R.: Topical anesthetic in endoscopy, critical evaluation with case report and survey of current opinion. Laryngoscope, 59: 1102, 1949.

22. Tella, R. A.: Reaction to cocaine used as topical anesthetic in bronchoscope. Arch. Otolar., 63: 115, 1956.

23. Williams, C. B.: Barbital to prevent toxicosis from local anesthetics. Laryngoscope, 37: 921, 1927 .

24. Martin, E. G.: Local anesthesia agents: preventive and emergency treatment of toxicity with especial reference to barbituric and derivatives J.A.M.A., 91: 555, 1929.

25. Barlow, R. A.: Value of barbital before local anesthesia. Ann. Otol. Rhin. Laryng., 38: 421, 1929.

26. Hou, K.: Prevention of cocaine intoxication in the field of bronchoesophagology. J. of Jap. Bronchesophag. Soc., 5: 70, 1954.

27. Suzuki, Y. et al.: Studies on experimental shock and its prevention in guinea pigs being applied stimulation to the palate. Keio J. Med., Vol. 7, Centenary Number, Nov., 1958. 


\section{EXPLANATION OF FIGURES}

Fig. 1. Liver of animal injected cacaine by submucosal injection in the palate. Congestion of blood in the central veins and the capillaries, and marked vacuolar degeneration of hepatic cells.

Fig. 2. Liver of animal given cocaine by subcutaneous injection in the abdominal wall.

No significant change.

Fig. 3. Liver in animal given cocaine by intravenous injection into the femoral vein.

No significant change.

Fig. 4. Liver of animal premedicated with chlorpromazine. No significant change.

Fig. 5. Lurg of animal given cocaine by submucosal injection in the palate. Congestion of blood in capillaries, hemorrhage of alveoli, edematous swelling of alveolar wall and atelectasis, and infiltration of small round cells around vessels.

Fig. 6. Lung of animal given cocaine by subcutaneous injection in the abdominal wall.

No significant change.

Fig. 7. Lung of animal given cocaine by intravenous injection into the femoral vein.

No significant change.

Fig. 8. Lung of animal premedicated with chlorpromazine.

No significant change.

Fig. 9. Kidney of animal given cocaine by submucosal injection in the palate. Hemorrhage in tubules.

Fig. 10. Kidney of animal given cocaine by subcutancous injection in the abdominal wall.

No significant change.

Fig. 11. Kidney of animal given cocaine by intravenous injection into the femoral vein.

No significant change.

Fig. 12. Kidney of animal premedicated with chlorpromazine. No significant Changes.

Fig. 13. Adrenal gland of animal given cocaine by submucosal injection in the palate.

Marked congestion of blood in capillaries of the cortex.

Fig. 14. Adrenal gland of animal given cocaine by subcutaneous injection in the abdominal wall.

No significant change.

Fig. 15. Adrenal gland of animal given cocaine by intravenous injection into the femoral vein.

No significant change.

Fig. 16. Adrenal gland of animal premedicated with chlorpromazine.

No significant change. 


\section{Fig. 1}

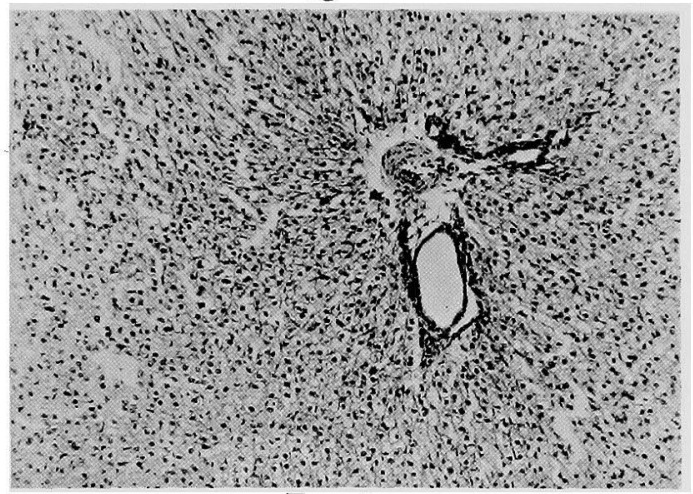

\section{Fig. 3}

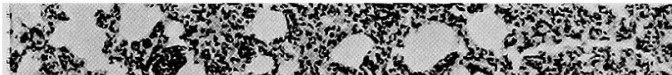
s. $x^{2}$,

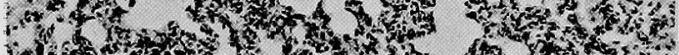

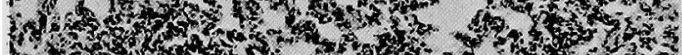

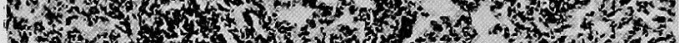

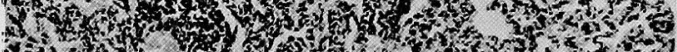

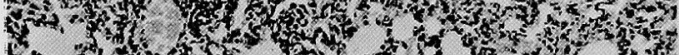

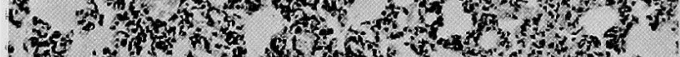
6. Th,

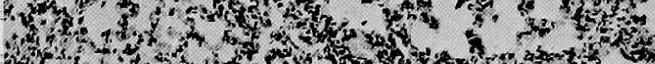

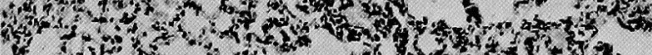
1.

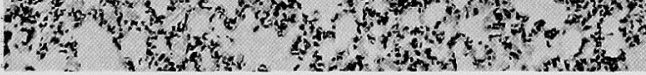
Fig. 5

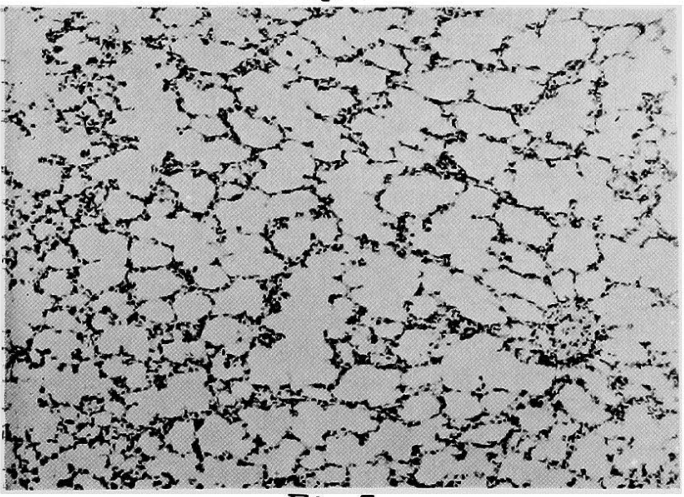
Fig. 7

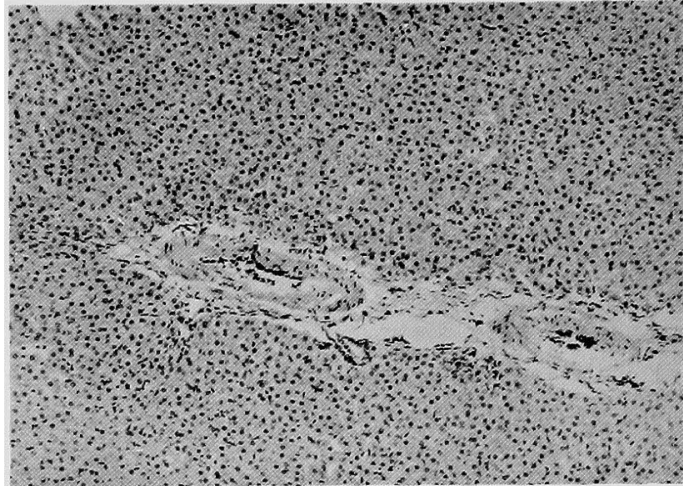

Fig. 2

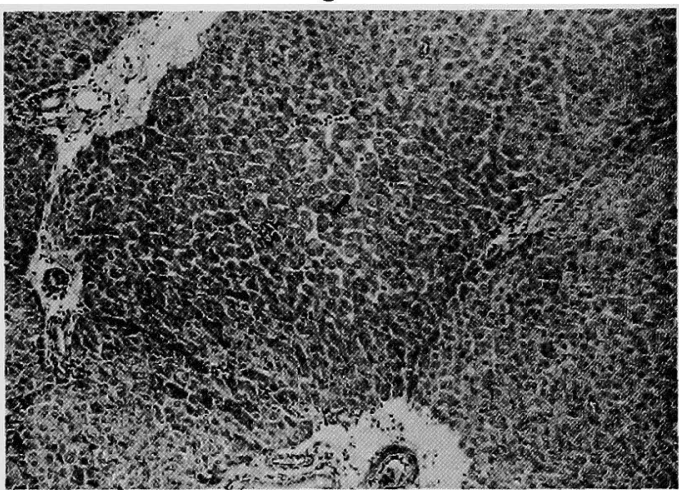

Fig. 4

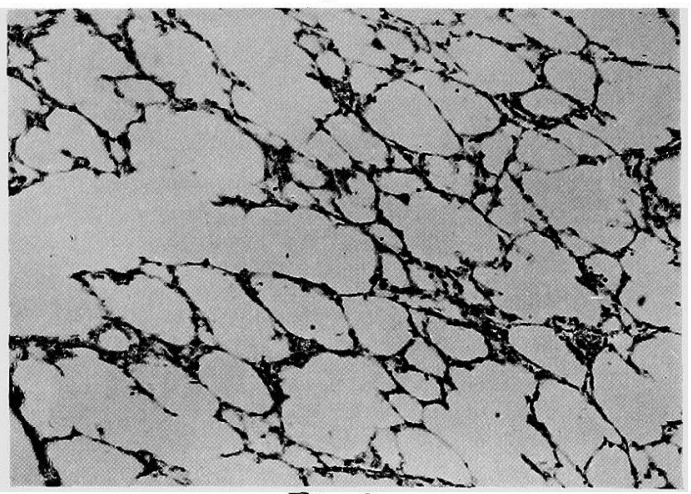

Fig. 6

to i. 1. Dit Fig. 8 


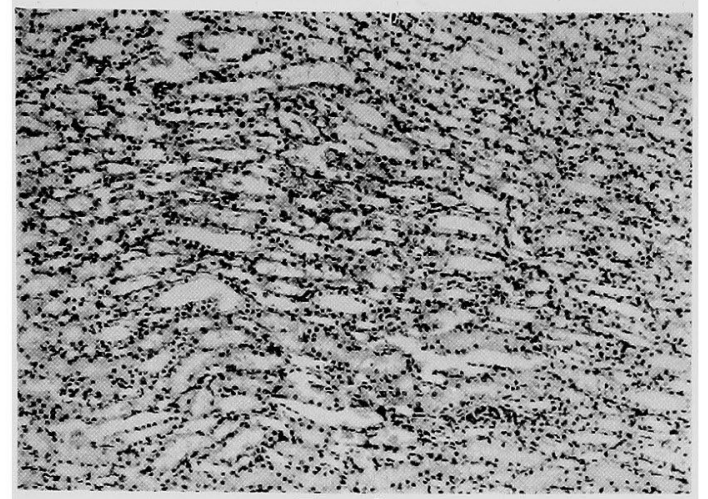
Fig. 9

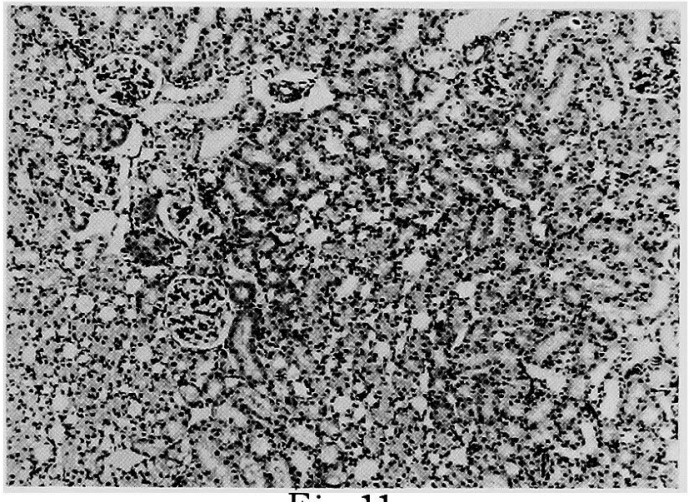
Fig. 11

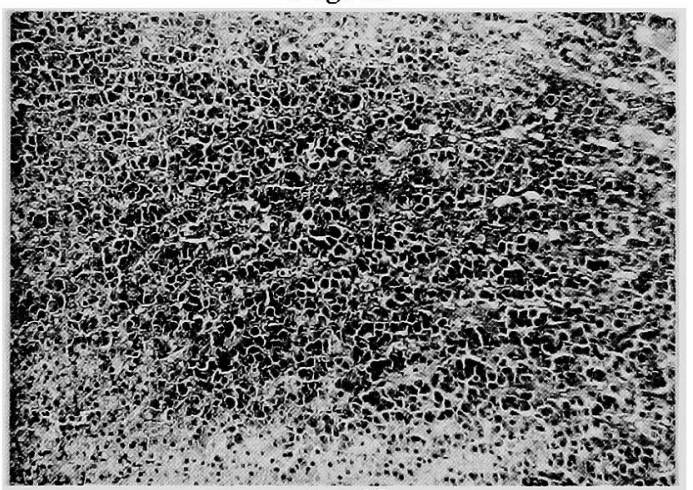
Fig. 13

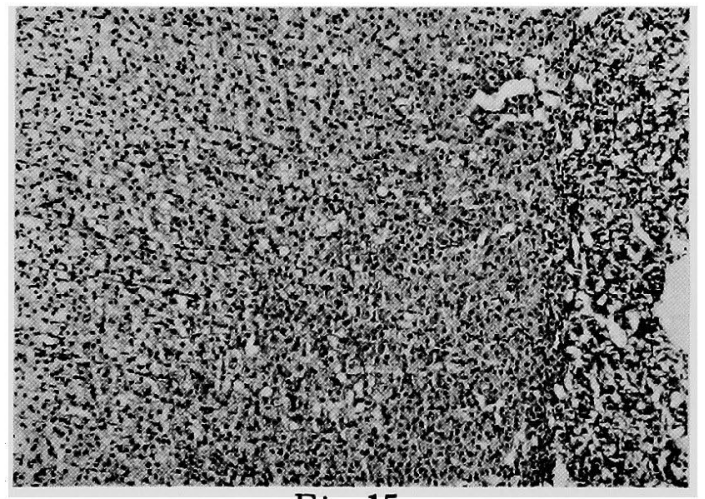
Fig. 15
3.

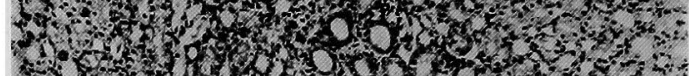

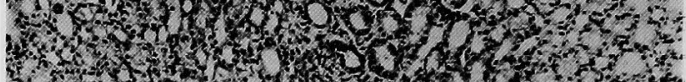

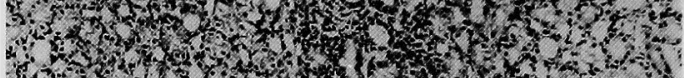

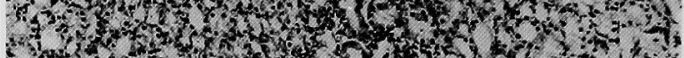
1.0. 3.t.

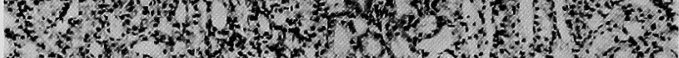

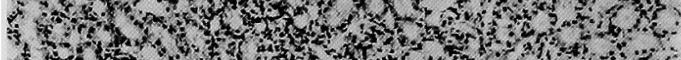

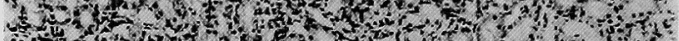

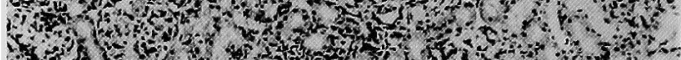

Fig. 10

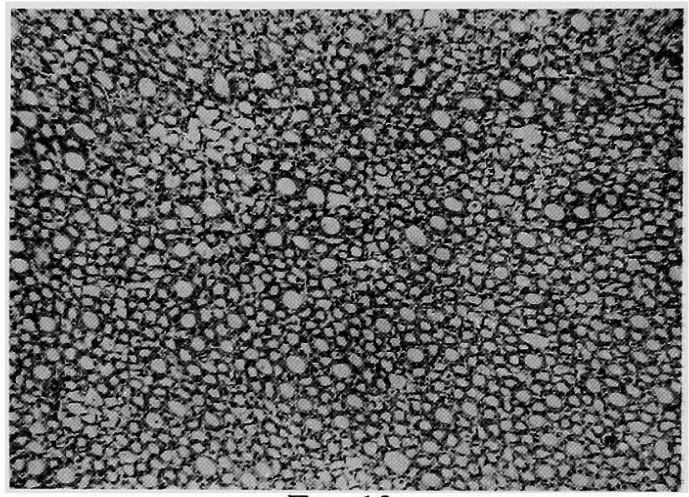

Fig. 12

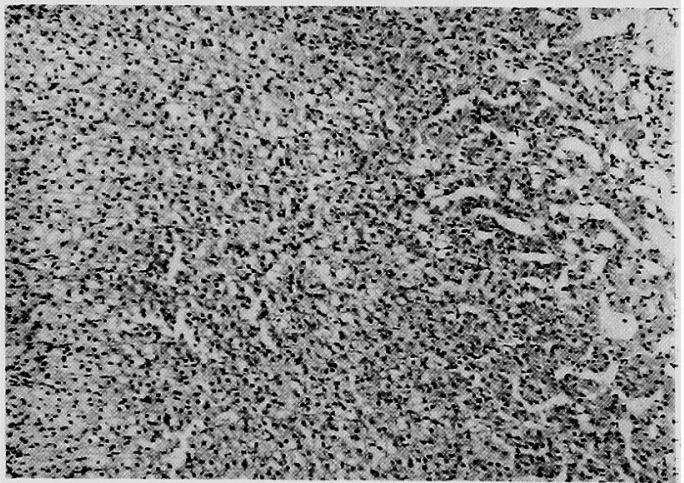

Fig. 14

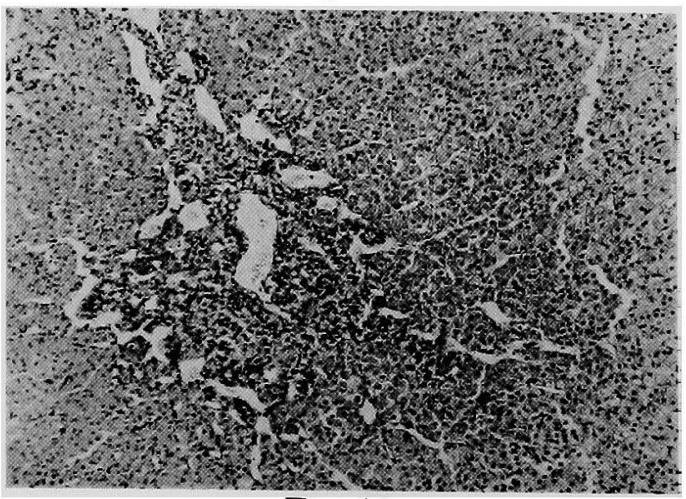

Fig. 16 